\title{
La mirada perdida: Ios libros del escritor invidente Gábor Molnár sobre la Región Amazónica
}

\author{
The Lost Gaze: Books on the Amazonian \\ Region by the Blind Writer Gábor Molnár
}

Mónika Szente-Varga *

\section{RESUMEN}

Una de las personas con influencia marcada sobre la imagen de la Amazonia, y en general, de la imagen de Brasil en Hungría en la segunda mitad del siglo XX, fue Gábor Molnár, capataz de una hacienda y miembro de una fallida expedición amateur a Brasil en 1930. Vivió, trabajó, cazó y recolectó especímenes en la Región Amazónica entre 1930 y 1932, hasta perder la vista en una explosión. Con el accidente se perdió un excelente tirador zurdo y nació un escritor apasionado, quien mecanografió sus historias ubicadas en Brasil a ciegas, con tenacidad, a través de varias décadas, convirtiéndose en uno de los autores más leídos en Hungría en los años 1960 y 1970. Este ensayo analiza, dentro del contexto de las relaciones húngaro-brasileñas, los factores que contribuyeron a la popularidad de sus textos.

Palabras clave: Brasil; imagen del país; literatura; naturaleza; Hungría, Amazonia.

\section{Abstract}

One of the people with a marked influence on the image of Amazonia, and in general, on the image of Brazil in Hungary in the second half of the 20th century was Gábor Molnár, foreman by profession and member of a failed amateur expedition to Brazil in 1930. He lived, worked, hunted and made animal collections in the Amazonian Region between 1930 and 1932, until he lost his sight in an explosion. Due to the accident, the excellent left-handed shooter was lost forever, and in his place a passionate writer was born, who typed his stories situated in Brazil, with tenacity, blindly, over various decades, turning himself into one of the most read authors in Hungary in the 1960s and 1970s. This essay, within the context of Hungarian-Brazilian relations, analyzes the factors that contributed to the popularity of his texts.

Keywords: Brazil; country image; literature; nature; Hungary, Amazonia.

\footnotetext{
* National University of Public Service, Faculty of International and European Studies, Budapest, Hungary. Szente-Varga.Monika@uni-nke.hu <https://orcid.org/0000-0001-7403-6960>
} 
Nunca miro cómo me caí en el foso, estoy ponderando cómo me trepo.

Gábor Molnár

El 27 de mayo de 1930 partió de Budapest una expedición amateur de tres húngaros hacia Brasil, con el fin de atrapar y disecar ejemplares para la colección de insectos del Museo Nacional de Hungría. Participaban Elemér Horváth, experto en insectos y ex guardia de museo en Constantinopla; Lajos Pusztai, zapatero, el mecenas de la empresa, y un joven de 22 años, Gábor Molnár, con una buena experiencia como mayoral de una hacienda, y tirador excelente.

La expedición fracasó aún antes de empezar. Al llegar a Brasil, Horváth y Pusztai se enfermaron y tuvieron que regresar a Hungría, lo que lograron vendiendo todo el equipo que llevaban. Molnár se quedó solo en Manaus, sin armas, y sin dinero. Empujado por su espíritu aventurero, no quiso rendirse. Fue ayudado por el zoólogo, taxidermista y coleccionista de origen húngaro Carlos Lakó (Szeged, 1895-Rio de Janeiro, 1960), quien le prestó cuchillos, hachas, cajas de hojalata para guardar culebras e incluso dinero para posteriores expediciones. También tuvo la oportunidad de conocer en Manaus a los coleccionistas alemanes, amigos de Lakó, Martin Braun, George Huebner y Walter Pretorius. De todos ellos recibió consejos prácticos, así como nombres y direcciones de personas a quienes podría vender animales disecados y pieles, en caso de que necesitara dinero (Molnár, 1940, p. 1-105). Molnár encontró trabajo en la hacienda de la compañía Ford en Boa Vista, más tarde llamada Fordlandia, donde se desempeñó como director de una de las fazendas o granjas. Alternó el trabajo con la cacería en y cerca del río Tapajós, y estuvo también cazando y coleccionando en los alrededores de los ríos Jatapú y Uatumã. A base de su sueldo con Ford y de la venta de los animales que cazaba o atrapaba, logró sostenerse y organizar nuevas excursiones a la selva, que hacía acompañado de uno o más caboclos. Mandó varias piezas de sus colecciones a casa, al Museo Nacional. Fue éste posiblemente uno de los mejores periodos de su vida. Amaba la naturaleza, la selva, que poco a poco iba conociendo, y pudo hacer algo similar a lo que había leído en sus lecturas juveniles preferidas, de cacería y de aventuras. Desafortunadamente, tras 20 meses de estancia, y debido a la detonación de un artefacto explosivo, que quiso desactivar, sufrió un accidente que casi le quitaría la vida. Y aunque sobrevivió, perdió la vista para siempre. En mayo de 1932, justamente dos años después de salir de la capital húngara, regresó a Budapest, ya invidente, con dos serpientes vivas. Aprendió a mecanografiar y empezó a redactar sus experiencias en Brasil. 
Primero en forma de textos cortos, que más tarde, con la práctica, se hicieron más largos y complejos, pero seguían ubicándose en la región amazónica, casi sin excepción. Con el paso del tiempo, Gábor Molnár se hizo un excelente cuentacuentos y se convirtió en uno de los escritores más leídos de Hungría en las décadas de 1960 y 1970.

Este ensayo busca y analiza las razones detrás de la popularidad de la obra de Gábor Molnár. Examina principalmente tres factores, que son los que podrían influir más significativamente: 1) la ubicación geográfica y el tema principal de los textos, Amazonia, Brasil; 2) la voluminosidad y variedad de la obra de Molnár; y 3) la importancia que el escritor le daba a mantenerse en contacto con el público lector. La principal fuente de esta investigación son los propios libros de Molnár, complementados con artículos de periódico y ensayos académicos, escritos en el campo de las relaciones húngaro-brasileñas. Así, siendo húngaros tanto la gran mayoría de las fuentes como el protagonista del ensayo, este escrito ofrece una perspectiva centro/este-europea de la Amazonia.

\section{El TEMA DE BRASIL EN EL CONTEXTO HÚNGARO-BRASILEÑO}

Los contactos húngaro-latinoamericanos fueron más bien esporádicos en el siglo XIX, y se intensificaron únicamente alrededor de algunos eventos, como por ejemplo la ola emigratoria desatada por el fracaso de la guerra de independencia húngara luchada contra los Habsburgo en 1848-1849. La emigración Kossuth, llamada así por el líder político independentista Lajos Kossuth, se dirigió también hacia los Estados Unidos y a través de este país, ya en números mucho más reducidos, a América Latina. Como consecuencia, a partir de los 1850-1860 comenzaron a llegar a Hungría y a ser publicados relatos de viaje y descripciones sobre lugares latinoamericanos. Su novedad consistía en que no se trataba de traducciones, sino que fueron elaborados por húngaros, para un público en casa, en lengua húngara. La mayoría de los ex revolucionarios fueron a países cercanos al lugar de su arribo original, los Estados Unidos: esto es, a México, o a los países de América Central y el Caribe. Brasil se puede considerar como un destino atípico. ${ }^{1}$ Existe sin embargo una memoria de viaje en forma de libro, escrito por el emigrante István Geőcze bajo el título Utazás Brazíliába és vissza [Viaje de ida y vuelta a Brasil], publicado en 1869-1870.

La abolición de la esclavitud en Brasil, seguida por la creciente demanda de mano de obra, coincidió en tiempo con una masiva emigración desde los territorios de la Monarquía Austro-Húngara, estado dual formado en 1867. 
Dicha ola migratoria formó parte del proceso que comenzó en los 1840 principalmente en Irlanda, y después su foco fue trasladándose hacia el este, pasando por tierras alemanas y escandinavas, hasta presentarse a finales del siglo XIX y principios del XX, en Italia, la Monarquía Dual y Rusia. Al torno del siglo los emigrantes por lo general se dirigieron a los Estados Unidos. Sin embargo algunos grupos, especialmente aquellos con recursos financieros muy reducidos, fueron a Brasil, aprovechando el pasaje pagado. Las experiencias de los recién llegados fueron tan poco satisfactorias, que el Ministro de Asuntos Interiores de Hungría restringió por decreto la emigración a Brasil desde finales del siglo XIX (Bencsik, 2003, p. 16).

Después de la Primera Guerra Mundial, el cambio de las fronteras en Europa Centro-Oriental, así como la crisis económica, contribuyeron a una nueva oleada de emigración. Su característica fue que los húngaros en su mayoría no partieron desde Hungría sino de los territorios cedidos a países vecinos por el tratado de paz, y por tanto viajaron con pasaporte rumano, checoslovaco etc. Por eso oficialmente no fueron considerados como húngaros por las autoridades latinoamericanas. Sin embargo, tendieron a preservar su identidad original y mantener - en la medida de lo posible - algún contacto con Hungría, puesto que las razones principales de su salida de Europa no fueron las dificultades sufridas en su país de nacimiento sino en otros. La ruta de dicha ola migratoria quedó alterada por las restricciones de entrada impuestas por los Estados Unidos. Algunos prefirieron ir a México o a Cuba, utilizando a dichos países como trampolín, y esperando llegar finalmente a la tierra de sus sueños, mientras otros escogieron América del Sur, en particular los países con costa atlántica, que "miraban hacia Europa". Las colonias húngaras más numerosas se formaron así en Brasil y en Argentina. Para la década de los treintas, cuando los primeros artículos de Gábor Molnár vieron la luz, se puede estimar el número de húngaros en Brasil entre 50 mil y 80 mil (Pongrácz, 2008, p. 35-36; Szilágyi, 2005, p. 147; Torbágyi, 2004, p. 45). Vivían mayoritariamente en la parte sureste del país, en los estados de São Paulo, Rio Grande do Sul, Rio de Janeiro, y en menor número, en Santa Catarina, Minas Gerais y Paraná.

"La imagen del mundo brasileño en la prensa húngara no concordaba ni con la importancia de la emigración húngara a Brasil, ni con el tamaño del país. Similarmente a las olas emigratorias anteriores, el 90\% de los artículos de prensa trataron asuntos europeos, mientras el resto del mundo estaba más bien representado por Rusia y Japón y, en cuanto a la emigración, por los Estados Unidos" (Igaz, 2016, p. 26). ${ }^{2}$ Además, la imagen que prevalecía sobre Brasil tendió a ser más bien negativa. En la primera mitad del siglo veinte no 
solamente se asoció con las bellezas de la naturaleza y con lo exótico, sino también con lo imprevisto, lo peligroso, lo salvaje y lo sangriento.

Brasil por tanto se convirtió en una ubicación perfecta para las novelitas de pacotilla, cuyos autores - por lo general húngaros, pero utilizando a veces seudónimos extranjeros para vender mejor - escogieron con gusto para sus escritos los países más conocidos de América Latina, los cuales formaron parte integrante de la imagen del continente: México y Brasil. En las décadas de 1930 y 1940 se publicaron más de dos docenas de folletines de pacotilla que llevan la palabra Mexikó, mexikói / México, mexicano en su título, y se conservan aún algunos títulos con brazil / brasileño (György, 1944; Magyar, 1940; Thurzó, 1942; Willant, 1940). Se trata de libritos de tamaño pequeño, de un valor literario dudoso, de precio barato, que en muchos casos fueron publicados como ediciones especiales de alguna revista. Se basaron en las ideas que la gente común tenía en Hungría sobre dichos países, y por tanto, nos pueden ofrecer una buena aproximación acerca de la imagen que prevaleció en Hungría acerca de América Latina, y de (la falta de) conocimientos al respecto (Szente-Varga, 2004, p. 95-105).

Para dar una idea, he aquí algunas frases del folletín cuyo protagonista, según sugiere el título (El pretendiente brasileño) proviene de o por lo menos estuvo en Brasil.

Estuvo sondeando con cautela. Quería saber quién era ese tipo de nombre raro y un poco ridículo: Schneller Mátyás Jimenez. ¡jimenez... qué nombre tan insensato! Se llama como si fuera un revolucionario español o un monje. Después de una semana se enteró de que su admirador secreto era tabernero, el propietario del restaurante-posada dedicado a los Tres dados, ubicado en las afueras de la ciudad. Se rumoreaba que el tabernero era un hombre aventurero, que no había vivido en Hungría por años o hasta décadas, sino que fue hacendado en América del Sur, tenía pampas, domesticaba llamas y puercoespines. Estos últimos son tan mansos como los borregos, pero son mucho más feos. (Thurzó, 1942, p. 12-13) ${ }^{3}$

La riqueza de Brasil en minerales, plantas y animales formó parte de su imagen en Hungría, así como la idea de que uno puede hacer mucho dinero en este país lejano, y que viven allá húngaros. Existió un cierto "sueño brasileño".

Los Bálványossy recibieron su blasón de nobleza del rey Bela IV. En la familia hubo generales, canónigos, propietarios de fortalezas en la edad media. Y si se necesita dinero, si el dinero cuenta, también hay en la familia un verdadero 
millonario. El tío Gazsi, o sea, Gáspár Bálványossy. Vive en América del Sur, donde tiene un verdadero castillo. Y la tierra que pertenece al castillo es del tamaño de la mitad de Hungría. (György, 1944, p. 8)

Los autores de estos folletines por lo general fueron personas que escribieron muchos textos similares, es decir, conocían bien los requerimientos del género, pero no necesariamente los lugares donde situaron sus historias. No faltaron en sus descripciones los clichés, estereotipos, exageraciones y equivocaciones. Al contrario de los escritores anteriores, Gábor Molnár vivió y trabajó en la selva brasileña, y por ende, sus textos - que empezaron a aparecer en la misma época que los folletines de pacotilla citados -, son más auténticos. Los analizaremos en detalle en los próximos capítulos.

La gente en Hungría tenía curiosidad acerca de Brasil a lo largo del siglo $\mathrm{XX}$. En el periodo de entreguerras gran parte de la motivación podría provenir de la presencia de grupos de inmigrantes húngaros en el país, así como de la fascinación por los territorios vírgenes y las aventuras. Por ejemplo, atrajo mucha atención y fue tema recurrente en la prensa húngara el misterioso fin del coronel y arqueólogo británico Percy Harrison Fawcett y su expedición en 1925 a la Amazonia. En la base de datos de periódicos digitalizados, Arcanum, se encuentran unas 80 noticias acerca de Fawcett publicadas entre 1925 y 1929 - años en los que el propio Molnár las pudo leer en Hungría - y alrededor de 100 más hasta 1940. A Molnár seguramente le sirvió de inspiración el trabajo del coronel. La dedicatoria de su primer libro, que vio la luz en 1940 bajo el título Kalandok a brazíliai őserdőben [Aventuras en la selva brasileña], dice: "A la memoria del explorador inglés Coronel Fawcett y sus compañeros, quienes junto con su expedición desaparecieron sin rastro en la selva brasileña”.

El tema de Brasil siguió atrayendo interés después de la Segunda Guerra Mundial. En la Hungría socialista fue muy difícil si no imposible viajar al extranjero, con la excepción de los países hermanos del mismo bloque ideológico. El liderazgo político encerró a los ciudadanos desde finales de los 1940 y los mantuvo así unos 40 años, tratando de aislarlos de "las malas influencias" del extranjero. Los húngaros que vivían fuera de Hungría se volvieron sospechosos, y hasta traidores a los ojos del régimen, independientemente de si emigraron después de la Segunda Guerra Mundial, fugándose del Ejército Rojo, o en el periodo de entreguerras por ser judío y/o simpatizar con las ideologías de izquierda y no aceptar el sistema Horthy. ${ }^{4}$ No se podía mantener contacto desde Hungría con grupos emigrantes húngaros. En estas décadas de los 1950, 1960 y 1970, los escritos de Molnár resultaron ser una "puerta chica", en el 
sentido de dar información sobre un país al que el ciudadano ordinario nunca podría llegar, y respirar cierta libertad:

Arrodillado junto a las cenizas blancuzcas del fuego de la noche anterior, Abilio lo atiza. Sube humo y salen llamas. Le pone ramas. Abrasa chasqueando el fuego para el desayuno. Abilio coloca el recipiente tiznado lleno de agua para preparar el café. El disco gigante anaranjado del sol sale de lo que parece una línea al otro lado del río, la selva del Jatapú. Se forma un puente dorado en el agua. Centelleando. Es magníficamente majestuoso. Como si uno pudiera cruzarlo para llegar a la otra orilla en la lejanía.

Estoy en el agua hasta medio muslo y admiro el panorama deslumbrador del sol saliente. La jaula de la anaconda colocada en el agua me sirve de jabonera. Me echo el agua con las dos manos y después me recuesto sobre ella. Es divertido tomar un baño junto a una anaconda, en particular si el animal ya está enjaulado. (Molnár, 1963, p. 44)

Las reglas y el ritmo de la selva amazónica fueron muy diferentes de los monótonos días de trabajo en Hungría, y la lectura de estos textos podría ser una manera de escapar, sentirse uno mismo en el lugar del cazador-explorador quien, además, puede tomar sus propias decisiones. Tanto la ubicación como el tema de los textos de Molnár contribuyeron a su popularidad.

\section{CANTIDAD Y VARIEDAD}

Otro factor que hay que tomar en cuenta al examinar la popularidad de Molnár es la voluminosidad y diversidad de su obra. Fue un escritor muy prolífico, con más de dos docenas de libros y muchos artículos, que publicó desde 1933 hasta su muerte, en 1980. La gran cantidad de escritos posiblemente es resultado de la pérdida de la vista. Redactar textos fue una manera de autocuración, pues al mecanografiarlos pudo revivir algunos episodios de su vida pasada en Brasil, y sentirse sano. Escribir se convirtió en su nueva vocación, en un vehículo para mantener cierta independencia financiera y tener un ingreso; una manera de "ser útil" y volver a encontrar su lugar en la sociedad.

En las décadas de los 1930 y 1940, principalmente redactó artículos: textos de divulgación científica sobre la fauna de la selva amazónica, así como cuentos de aventura y de cacería, que se desarrollan igualmente en la región del Amazonas. Publicó su primer libro, un relato de viajes, en 1940 bajo el título 
Kalandok a brazíliai öserdöben [Aventuras en la selva brasileña] (Molnár, 1940), que fue seguido por otros dos, dirigidos en particular al público infantil: A kutyafejü szikla [La roca en forma de cabeza de perro] (Molnár, 1942) y RyKe a Matto Grosso ősvadonában [Ry-ke en la selva virgen de Mato Grosso] (Molnár, 1944).

A partir de 1945 comenzó una nueva oleada de emigración desde Hungría. Primero los que colaboraron con el gobierno de ultraderecha, después los que huían del Ejército Rojo, seguidos por los que no querían vivir en un sistema socialista (Kaczúr, 1989):

Después de la guerra, las dificultades para ganar un sustento y, por desgracia, las desoladoras memorias conectadas con el conflicto mundial, hicieron que varias personas planearan emigrar a Brasil. Puesto que el idioma oficial es el portugués, es de suma importancia tener un conocimiento básico de esta lengua. Pero en húngaro carecemos tanto de un diccionario como de un manual para aprender... (Békefyné Kacsóh, 1947, p. 3)

La misma obra a la que se hace aquí referencia incluye breves explicaciones de la pronunciación y de las estructuras gramaticales, así como un diccionario húngaro-portugués (de Brasil). El mismo año vio la luz el libro Brazíliai portugál nyelvkönyv [Manual del portugués brasileño] elaborado por Ferenc Kordás, profesor universitario de portugués (Kordás, 1947). Su libro consta de 30 unidades que se dividen respectivamente en lectura, vocabulario, gramática y ejercicios correspondientes. La demanda sobre las posibilidades de aprender algo de portugués y adquirir datos y conocimientos acerca de Brasil, también fue percibida por Gábor Molnár, que publicó su Magyar-portugál szótár [Diccionario húngaro-portugués] (Molnár, 1947/1948), el cual consta de un diccionario alfabético, seguido por una compilación temática de palabras, como por ejemplo materiales, vida estatal, familia, salud pública, fotografía, ocupaciones, transporte, insectos, pájaros, flores. Después hay un capítulo dedicado a las conversaciones, y otro a la gramática. El libro termina con un apéndice de más de 50 páginas sobre la vida contemporánea en Brasil, señalando inclusive alternativas para futuros asentamientos.

Amén de las llanuras de Brasil y de los demás países sudamericanos, las regiones cubiertas de selva y de bosques se prestan también para poblamiento, siempre que se encuentren cerca de caminos que permitan el transporte, y también de ciudades, grandes y pequeñas. La elección del lugar se puede basar en los productos de la región. Entre estos se incluyen el caucho, la batata, el cacao, el café; 
pieles de animales salvajes, de reptiles y de vaca; maderas, y muchos otros productos agrícolas y hortícolas que ofrecen amplia posibilidad para trabajar y al mismo tiempo obtener un sustento digno. Este último es el verdadero deseo de todo el mundo. (Molnár, 1947/1948, p. 136)

Las tres publicaciones arriba mencionadas se pueden considerar pro-emigratorias. Sin embargo la esperada ola fue cortada por la toma de poder del partido comunista en Hungría y el cierre de las fronteras para el final de la década.

El periodo estalinista bajo el liderazgo de Mátyás Rákosi no favoreció la producción literaria de Molnár, y fue en el sistema de Kádár (noviembre de 1956-1988) $)^{5}$ que alcanzó sus mayores éxitos como escritor. ${ }^{6}$ Publicó con regularidad, en su mayoría acerca de temas relacionados con el Amazonas, y en parte con Mongolia, que fue su otra pasión. En las décadas de 1960 y 1970 vieron la luz 15 libros suyos, en su mayoría relatos, basados en parte en sus propias experiencias en Brasil en 1930-1932, y en parte en las noticias que recibía por la radio, de sus amigos, etcétera, y también como producto de su imaginación. Maduró como un excelente cuentacuentos, que mezclaba las descripciones de la fauna y flora de la selva con algunas de sus acciones diarias (como la caza y sus deberes en la hacienda de Ford en Boa Vista), y otras actividades. Vamos a leer algunos extractos:

Batí las palmas ante la choza de Abelardo Ibiraba. Pido permiso para entrar. Adelante - dice una voz desde dentro. Paso. Hay una mecha de petróleo que ahuma. Abelardo se encuentra al otro lado de la choza, friendo pescado bajo la gotera. El humo del carbón de leña cubre todo.

Buenas tardes - aprieto la mano del caboclo. Pongo mi sombrero sobre el baúl donde Abelardo me ofrece lugar para sentarme.

¿Puedo ofrecerle unas pirañas rojas recién fritas? - pregunta.

No, gracias - digo. Esto es la cortesía. Empiezo a comer las pirañas espinosas servidas sobre un plato esmaltado únicamente después de la segunda insistencia. Junto al canal del matadero de la fazenda de abajo que llega al agua del río, siempre hay un montón de pirañas rojas. Tienen el mismo tamaño que los gardíes del Danubio, en casa.

$[\ldots]$

Estamos remando. El poder de la selva llega hasta mí y me oprime. Nuestros ri- 
fles, arpones y herramientas arreglados en fila, una fuerza todopoderosa. Mis experiencias crecen siguiendo las huellas de Abelardo. Traen una nunca esperada seguridad cazadora y pescadora, con resultados rápidos. Quiero aprender y madurar con la naturaleza y la selva, con todo lo que encuentro aquí. En este gigantesco laberinto construido por la naturaleza, en donde el sinfín de vidas que luchan entre ellas muestran mil caminos, el hilo de Ariadna son las experiencias de Abelardo y los demás caboclos. Cuando pienso en la razón de mi vida extraviada aquí, y doy vueltas a la idea de echar raíces, reflexiono también acerca de las sensaciones que el entorno ejerció sobre mí, y siento una fuerza creciente. No es suficiente provocar el disparo moviendo el gatillo del Winchester, echar el lazo del bastón para atrapar culebras, capturar las arañas gigantes echándolas de sus nidos con agua, o emborrachar a las mariposas multicolores con algún líquido atractivo, sino que hay que amar este mundo con los brazos abiertos, vivir con él y en él. (Molnár, 1964, p. 9, p. 223)

Hay que recalcar que Molnár elaboró este texto - similarmente a la mayoría de sus libros - más de 30 años después de haber vivido en Brasil. Y reiterar que por tanto lo que muestra no es el país en los sesentas o setentas, sino el Brasil en tiempos de la gran crisis financiera mundial. Otra característica de sus libros es que dentro de una historia encapsula otras, al hacerles a los personajes contar sus relatos, y que el protagonista - que es él mismo - está escribiendo en el propio cuento.

En los 1970, tras haber cumplido 60 años, publicó algunas obras biográficas, que reflejan muy bien su capacidad de pertenecer a dos mundos distintos. En el título de la primera, Makk és Jaguár [Bellota y jaguar] (Molnár, 1972) la bellota simboliza las montañas del Bakony, al norte del lago Balaton, en Hungría, donde vivían sus abuelos maternos y pasó una parte feliz de su niñez, mientras el jaguar es una referencia a la selva amazónica, donde no estuvo más de 20 meses, pero la experiencia le marcó la vida y le sirvió de tema para una carrera literaria de varias décadas. Uno de sus escritos más profundos es Éjbe zuhant évek [Años arrojados a la noche] (Molnár, 1973) en que cuenta el periodo inmediatamente posterior a su accidente: desde la pérdida de la esperanza de poder volver a ver, seguida por su recuperación mental y el esfuerzo para aprender a mecanografiar, hasta la publicación de sus primeros textos. Su tercera autobiografía, titulada A Bakonytól Amazóniáig [Desde Bakony hasta Amazonia] (Molnár, 1978) fue el último libro publicado antes de su muerte accidental por intoxicación con monóxido de carbono en 1980.

Fue en 1972 que Molnár logró regresar a Brasil (Escritor..., 1972, p. 6), ${ }^{7}$ gracias a la invitación oficial del Itamaraty que cubría sus gastos durante la 
visita, y a la generosidad de su amigo, el artista gráfico Endre Szász (19262003), quien le compró los boletos de avión. Estuvo en Brasil del 3 de octubre hasta el 15 de diciembre de 1972. Resumió estas experiencias en el libro Én kedves Amazóniám [Mi querida Amazonia] (Molnár, 1975), que es un relato de viajes extraordinario, sobre todo tomando en cuenta que fue hecho por una persona que no podía ver, y por tanto muchas de las impresiones que recibía fueron transmitidas por las personas - varios húngaros - que le acompañaban, lo ayudaban con la organización, etcétera. Encontramos entre ellos al profesor Paulo Rónai; ${ }^{8}$ a Edmundo Linka, maestro del Colegio de Santo Amerigo de São Paulo; al arqueólogo Lehel de Silimon (originalmente apellidado Szőnyi), colaborador del Museo Rondon en Cuiaba y de la Companhia de Desenvolvimento do Mato Grosso (Condemat); al monje Szervác Magyar, y naturalmente a diplomáticos húngaros trabajando en Brasil: el embajador János Beck y el agregado cultural András Gulyás. ${ }^{10}$ La visita de Molnár terminó con una presentación de su libro Aventuras na mata amazônica. El texto fue traducido por Éva Soltész, hermana menor de Paulo Rónai y revisado por la destacada escritora brasileña Rachel de Queiroz (1910-2003).

Aparte de los géneros arriba mencionados (autobiografía, relato de viaje, cuento de aventuras), Molnár también redactó una biografía en forma de relato. En A dzsungel doktora [El doctor de la selva] (Molnár, 1967) el autor narra la vida del Dr. Vital Brazil Mineiro da Campanha, inventor del suero contra veneno de serpientes, dentro del contexto histórico y social de Brasil, con descripciones detalladas de diferentes tipos de víboras. En 1972, cinco años después de la publicación de este libro biográfico, Molnár visitó durante su estancia en São Paulo el Instituto Butantan, que Vital había encabezado como primer director. Molnár menciona en su relato sobre este viaje que las dos ediciones húngaras de El doctor de la selva se encontraban en la biblioteca de la institución (Molnár, 1975, p. 147).

En resumen, los textos de Gábor Molnár tienen en común el tema de Brasil, pero pertenecen a varios géneros. Esta diversidad ayudó a atraer y a ampliar el círculo lector. Molnár también hizo adaptaciones de sus obras: textos cortos para cómics y cuentos que se actuaban en la radio. Estas adaptaciones podían captar a un público relativamente amplio y ganar de esta manera futuros lectores. Fue un escritor querido tanto por niños como por adultos. Puesto que su obra abarca casi medio siglo, sus textos llegaron a varias generaciones incluso dentro de las mismas familias. Otra indicación de su popularidad es que varios libros suyos tuvieron dos o más ediciones. 
Algunos libros de Gábor Molnár fueron publicados en el extranjero, en particular en los países socialistas, bien como traducciones ${ }^{11} \mathrm{o}$ en números muy reducidos - con tirajes de alrededor de 500 ejemplares -, directamente en húngaro para las comunidades húngaras fuera del país. Su mayor éxito fue sin duda la publicación de Aventuras na mata amazônica por LISA en Brasil (Molnár, 1970).

\section{CONTACTO CON LOS LECTORES Y MÉTODO DE TRABAJO}

Mantener contacto con las personas que leían sus textos fue de suma importancia para Molnár. Iba con frecuencia a encuentros organizados entre autores y el público lector; a ferias de libros, y también a escuelas para ofrecer pláticas a los estudiantes sobre la vida en la selva. A partir de 1959, cuando más de una década después de la Segunda Guerra Mundial se terminó la reconstrucción de la cueva artificial en el parque zoológico de Budapest, Molnár empezó a tener allí una serie de ponencias de divulgación científica (Persányi; Hanga, 2008, p. 108). Se dice que uno de los mayores regalos para él era que algún lector le llamara por teléfono para platicar sobre sus textos.

Varias de las personas que leían sus cuentos de la selva pero no conocían sus autobiografías, no sabían que era ciego. Tal era el mundo visual lleno de imágenes de sus textos.

Estoy trabajando con las pupas de cáscara dura, en agua hirviendo y borboritando, para preservarlas. El cielo es azul. Al otro lado la selva aparenta una línea negra, en su centro se encuentra la boca del Jatapú. A la derecha la repunta baja del solitario mercader sirio se desvanece con la humedad de la distancia. Bajo condiciones de tiempo idóneas, se puede ver su diminuta choza. Sus almacenes no. Nos rodea un profundo silencio. Después de un trabajo bien hecho, me gustan las tardes y las noches. La selva está llena de vida. Lo único que tenemos que hacer es sacarle la presa. No nos falta energía o ánimo. Mis cajas de hojalata se llenan de insectos. Nunca puedo pasar el tiempo sin hacer nada. No tengo ningún talento para perder el tiempo. Siempre estoy lleno de una cierta tensión, como si algo me estuviera insistiendo: hazlo, porque tienes poco tiempo. Me apresuro. Mis hombres - como si fuesen engranajes vivos - toman el ritmo. (Molnár, 1963, p. 106)

Molnár insistió toda la vida en que a pesar de que no veía el exterior, mantenía una vista interna, es decir, era capaz de conjurar una imagen, a base de las experiencias de sus primeros veinte años. 
Sin duda, tratándose de una persona ciega, sale la cuestión sobre su manera de trabajar. Dijo Molnár en una entrevista: "Me levanto a las 2-3 de la madrugada. Me acomodo junto a mi máquina de escribir y golpeteo las experiencias y memorias antiguas. En estos momentos solamente estoy presente físicamente enfrente de la máquina, pero mi alma anda lejos, tanto en tiempo como en espacio. Mi periodo de creación es la madrugada. Las personas que me ayudan llegan a las ocho, ocho y media de la mañana. Revisamos y corregimos los textos juntos" (Bocskai, 1969).

$\mathrm{Al}$ principio trabajó con una ayudante. Su tarea no se restringía a los textos, sino que también acompañaba al escritor a varios lugares fuera de la casa, ya se tratara de una oficina editorial, una presentación, etcétera. A Molnár no le gustaba usar el bastón de los ciegos. No quería que la gente le tuviera pena. Llevaba simplemente lentes oscuros y prefería llegar tomado del brazo de su acompañante. Su vanidad - en el buen sentido - le ayudó para no dejarse vencer. Quiso tener una vida completa y exitosa. Y la obtuvo a través del amor (se casó y tuvo tres hijos) y a través de la literatura. Para él, escribir no solamente fue una profesión sino una pasión y obsesión a la vez. Con la fama, se multiplicaron los pedidos - ya fuera de textos o para contar con su presencia -, así como la necesidad de que le leyeran otros libros, artículos, cartas que recibía, etcétera. Consecuentemente, hubo periodos cuando aparte de los miembros de la familia, contó con varias ayudantes.

A Molnár le importaba mucho la calidad de sus textos. Al aparecer nuevas ediciones de sus obras, volvía a repasarlas. Algunos libros suyos fueron revisados por académicos antes de ser publicados, aunque no se tratara de textos científicos. Eran relatos de cacería, de aventuras, con muchos detalles de ciencias naturales, incluyendo explicaciones sobre la apariencia física y el comportamiento de animales, descripciones de plantas, etc. El supervisor científico del libro Jaguárországban [En el país de los jaguares] (Molnár, 1960) fue el Dr. István Boross, director general del Museo de Ciencias Naturales, y para Pálmakunyhó az őserdőben [Cabaña de palma en la selva], el Dr. Csaba Anghy, director general del parque zoológico de Budapest.

\section{LEGADO}

Los libros de Gábor Molnár alcanzaron un total de más de un millón de ejemplares publicados hasta su muerte en 1980 (Domonkos, 2007). Si únicamente tomáramos en cuenta sus escritos, Molnár contribuyó de una manera significativa a la formación de la imagen de Brasil en Hungría a través de varias 
décadas, y sirvió como inspiración para futuros investigadores, como el ornitólogo József/José Hidasi (nacido en Makó, 1926) ${ }^{12}$ y el zoólogo Attila Bankovics (nacido en Jákfalva, 1944). ${ }^{13}$ Pero también hay que recordar que Gábor Molnár antes de ser escritor había sido cazador y coleccionista aficionado (y siguió siéndolo en su alma toda su vida), quien había mandado piezas desde Brasil al Museo Nacional de Hungría a principios de los 1930. Hay referencias a estos envíos en su correspondencia y obras, pero, por desgracia, queda muy poco en la actualidad de lo que llegó originalmente.

Tanto la Segunda Guerra Mundial, en la que Budapest se convirtió en una ciudad sitiada por más de cien días, como la revolución húngara de 1956, durante la cual los dos edificios que albergaban las colecciones de ciencias naturales fueron arrasados por las llamas, ${ }^{14}$ hicieron que gran parte de las piezas que Molnár había mandado a casa desde Brasil se perdieran para siempre. Los robos internos con fines de lucro en la colección de mariposas del Museo de Ciencias Naturales a finales de los 1940 y principios de 1950 aumentaron las pérdidas (Bálint; Katona, 2014, p. 45-46). Uno de los insectos extraordinarios que aún se preserva, es un escarabajo titán (Titanus giganteus) de casi 14 cm (Merkl, 2011).

El parque zoológico de Budapest fue uno de los lugares preferidos del niño Molnár en la capital. Cuando regresó de Brasil en 1932, ya ciego, trajo consigo tres culebras vivas. Una pereció en el viaje. Regaló las otras dos al zoo. Desafortunadamente, tuvieron que ser alimentadas artificialmente, y no duraron mucho. ${ }^{15}$

Por casi 40 años, no se han publicado libros de Gábor Molnár; en la actualidad la gran mayoría de los escolares en Hungría no conocen su obra. En lugar de ser conocido en todo el país, como lo era, hoy es más bien conocido en su ciudad predilecta, Ajka, en cuya cercanía vivían sus ancestros maternos. El museo urbano (Városi Múzeum) cuenta con una sala Gábor Molnár que alberga la colección que donó a la ciudad, así como su escritorio y su máquina de escribir. Hay un busto de bronce del escritor en el centro de Ajka (obra de László Márton, 1987) y una estatua de cuerpo completo tallada en madera en las afueras, en Csingervölgy (obra de József Bálint, 2018). Varias instituciones educativas (escuela primaria y guardería) llevan su nombre, y organizan competencias, conmemoraciones, etc. con Molnár como su tema. Con el fin de organizar las fiestas para el centenario de su nacimiento (2008), así como para preservar su legado en general, fue fundada en 2006 la asociación "Bakonytól Amazóniáig” Molnár Gábor Társaság, con sede en Ajka. ${ }^{16}$ 


\section{CONSIDERACIONES FINALES}

Después de la caída del socialismo en Hungría, hubo una contra-reacción hacia el sistema que había marcado al país por cuarenta años tras la Segunda Guerra Mundial, y en cierta medida hacia las personas que fueron exitosas en ese periodo. El auge de Gábor Molnár como escritor tuvo lugar en las décadas de 1960 y 1970, cuando fue uno de los autores más vendidos, hecho que inevitablemente lo vinculó con los años del socialismo. No obstante, el contenido ideológico de sus libros es poco y no afecta el objetivo central del texto, ni tampoco el pleno disfrute de su lectura.

Es posible que el público lector en Hungría redescubra a Gábor Molnár en el futuro, pero sus libros nunca alcanzarán el tiraje que tuvieron en la época Kádár. La razón principal es que el mercado de libros ha cambiado de una manera radical en Hungría y ahora es un terreno altamente competitivo y comercial. En menor grado también afecta el hecho de que en la actualidad se puede obtener información acerca de la Amazonia de varias fuentes, y las obras de Molnár serían solo algunas entre muchas. Asimismo, desde hace décadas las fronteras están abiertas y se puede viajar a Brasil.

A unos treinta años tras el fin del bloque socialista, ya creció más de una generación en Hungría que no tiene experiencia personal del sistema Kádár y, por otro lado, los que lo vivieron tienden cada vez más a recordar lo bueno y olvidar lo malo. La contra-reacción que mencioné al principio del capítulo empezó a transformarse gradualmente en una cierta nostalgia. Este sentimiento podría contribuir a la reedición de los libros de Molnár, pero hay que recalcar que sus obras no son impresiones del socialismo en Hungría. En su mayoría muestran a Brasil, y específicamente al de una época anterior, la del periodo de la gran crisis financiera mundial.

El valor literario de los textos de Gábor Molnár no ha cambiado con el tiempo; siguen siendo lecturas que deleitan. Las podemos leer como cuentos, relatos de viaje, etcétera, y también como fuentes históricas, porque son escritos que nos pueden aproximar al ambiente de un Brasil de hace casi un siglo. Preservar su legado e introducirlo en la vida académica sudamericana es la tarea de la parte húngara, porque siempre - y naturalmente - ha habido y hay más interés en Hungría hacia Brasil que al revés, del país que ocupa casi la mitad de América del Sur, hacia un estado de tamaño 80 veces menor, ubicado en la parte centro-oriental de Europa. 


\section{Libros de GÁbor Molnár aCerca de TEMAS RELACIONADOS CON BRASIL ${ }^{17}$}

MOLNÁR, Gábor. Kalandok a brazíliai őserdőben [Aventuras en la selva brasileña]. Budapest: Singer és Wolfner, 1940.

MOLNÁR, Gábor. A kutyafejü szikla [La roca en forma de cabeza de perro]. Budapest: Singer és Wolfner, 1942.

MOLNÁR, Gábor. Ry-Ke a Matto Grosso ösvadonában [Ry-ke en la selva virgen de Mato Grosso]. Budapest: Új Idők, 1944.

MOLNÁR, Gábor. Magyar-portugál szótár: nyelvtan, beszélgetések [Diccionario húngaro-portugués: gramática y conversación]. Budapest: Vajna és Bokor, 1947/1948.

MOLNÁR, Gábor. Jaguárországban [En el país de los jaguares]. Budapest: Gondolat, 1960.

MOLNÁR, Gábor. Pálmakunyhó az öserdőben [Cabaña de palma en la selva]. Budapest: Gondolat, 1963.

MOLNÁR, Gábor. Ahol az ösvény véget ér - Észak-Brazília őserdeiben [Donde el sendero termina - en los bosques del Norte de Brasil]. Budapest: Szépirodalmi Könyvkiadó, 1964.

MOLNÁR, Gábor. A dzsungel doktora [El doctor de la selva]. Budapest: Gondolat, 1967.

MOLNÁR, Gábor. Aventuras na mata amazônica. [Traducción del libro Kalandok a brazíliai őserdőben (Aventuras en la selva brasileña)]. São Paulo: LISA, [1970].

MOLNÁR, Gábor. Makk és Jaguár [Bellota y Jaguar]. Budapest: Szépirodalmi Könyvkiadó, 1972.

MOLNÁR, Gábor. Éjbe zuhant évek [Años arrojados a la noche]. Budapest: Szépirodalmi Könyvkiadó, 1973.

MOLNÁR, Gábor. Én kedves Amazóniám [Mi querida Amazonia]. Budapest: Szépirodalmi Könyvkiadó, 1975.

MOLNÁR, Gábor. A Bakonytól Amazóniáig [Desde Bakony hasta Amazonia]. Budapest: Szépirodalmi Könyvkiadó, 1978.

\section{REFERENCIAS}

BÁLINT, Zsolt; KATONA, Gergely. Lepkeírások [Relatos de mariposas]. Hatvan: Széchenyi Zsigmond Könyvtár, 2014.

BANKOVICS, Attila. Molnár Gábor madártani megfigyelései és gyűjtései Brazíliában [Las observaciones y recolecciones ornitológicas de Gábor Molnár en Brasil] In: TATAI, Zoltán (ed.). Emlékezés Molnár Gáborra születésének 100. évfordulóján 
[Conmemorando el centenario del nacimiento de Gábor Molnár]. Ajka: "Bakonytól Amazóniáig" Molnár Gábor Társaság, 2008. p. 77-88.

BÉKEFYNÉ KACSÓH, Magda. Brazil-portugál magyar nyelvkönyv és szótár [Manual y diccionario del portugués brasileño]. Budapest: Weitz Ny., [1947].

BENCSIK, Péter. A magyar úti okmányok története 1867-1945 [Historia de los documentos de viaje húngaros, 1867-1945]. Budapest: Tipico Design Kft., 2003. p. 10-36.

BOCSKAI, Imre. A rendkívüli ember [El hombre extraordinario]. Vakok Világa, Budapest: Magyar Vakok és Gyengénlátók Országos Szövetsége, v. 30, mayo 1969.

DOMONKOS, János. Vakon teljesedett ki az életműve [Su obra alcanzó la plenitud ya estando ciego]. Vakok Világa, Budapest: Magyar Vakok és Gyengénlátók Országos Szövetsége, v. 68, abril 2007.

ESCRITOR húngaro na Academia. Folha de S. Paulo, p. 3, 6 out. 1972.

GYÖRGY, László. Brazíliai nagybácsi [El tío brasileño]. Budapest: Nemzeti Figyelő, 1944.

IGAZ, Levente. Brazília és a brazíliai magyar emigráció a két világháború közötti magyar olvasóközönség szemével [Brasil y los húngaros en Brasil desde la perspectiva del público lector en Hungría entre las dos guerras mundiales]. In: PÁL, Ferenc (ed.). Hidak és Áthallások: Tanulmányok a brazil-magyar kapcsolatok köréből [Estudios acerca de las relaciones húngaro-brasileñas]. Budapest: ELTE Eötvös Kiadó, 2016. p. 25-41.

KACZÚR, Ágnes. Brazíliai magyarság a két világháború között 1920-1941 [Húngaros en Brasil entre las dos guerras mundiales, 1920-1941]. 1989. Disertación (Doctorado en Historia) - Szegedi Tudományegyetem. Szeged, 1989.

KORDÁS, Ferenc. Brazíliai portugál nyelvkönyv [Manual del portugués brasileño]. Budapest: Lingua, 1947.

MAGYAR, Tibor. A brazíliai fenevad [Bestia brasileña]. Budapest: [s. n.], 1940.

MERKL, Ottó. Molnár Gábor és az óriáscincér: Mender Ákos nyomozása Molnár Gáborról és a cincérről [Gábor Molnár y el escarabajo titán: La investigación de Ákos Mender acerca de Gábor Molnár y el escarabajo]. 29 set. 2011. Disponible en: https://archiv.magyarmuzeumok.hu/targy/342_molnar_gabor_es_az_oriascincer. Acceso en: 29 dez. 2018.

NAGY, Enikő. A Magyar Természettudományi Múzeum tragédiája 1956-ban [La tragedia del Museo de Ciencias Naturales de Hungría en 1956]. 19 out. 2014. Disponible en: http://ujkor.hu/content/a-magyar-termeszettudomanyi-muzeum-tragediaja-1956-ban. Acceso en: 29 dez. 2018.

PERSÁNYI, Miklós; HANGA, Zoltán. Molnár Gábor és az Állatkert [Gábor Molnár y el Parque Zoológico]. In: TATAI, Zoltán (ed.). Emlékezés Molnár Gáborra születésének 100. évfordulóján [Conmemorando el centenario del nacimiento de Gábor 
Molnár]. Ajka: "Bakonytól Amazóniáig” Molnár Gábor Társaság, 2008. p. 107-109.

PONGRÁCZ, Attila. A São Pauló-i magyarság 1945-1990 [Húngaros en São Paulo, 1945-1990]. 2008. Disertación (Doctorado en Historia) - Szegedi Tudományegyetem. Szeged, 2008.

SPIRY, Zsuzsanna. Uma ponte cultural alicerçada sobre os pilares da literatura. A obra de Paulo Rónai. In: KÓBORI, Sarolta; DEÁK, Máté; VIZENTIN, Marilena; HARGITAI, Evelin Gabriella (ed.). A presença húngara no Brasil: anais das I e II conferências sobre a Presença Húngara no Brasil. Pécs: Publikon, 2017. p. 105-118.

SZENTE-VARGA, Mónika. Imagen de México en las publicaciones de pacotilla en Hungría. Acta Scientiarum Socialium, Kaposvár: KTE, t. 15, p. 95-105, 2004.

SZILÁGYI, Ágnes Judit. A brazil egyházpolitikai válság korai előjele és magyar szereplöje: Carlos Kornis de Totvárad [Los tempranos agüeros de la crisis brasileña de las políticas eclesiásticas y su actor húngaro: Carlos Kornis de Totvárad]. In: PÁL, Ferenc (ed.). Hidak és Áthallások: Tanulmányok a brazil-magyar kapcsolatok köréböl [Estudios acerca de las relaciones húngaro-brasileñas]. Budapest: ELTE Eötvös Kiadó, 2016a. p. 115-124.

SZILÁGYI, Ágnes Judit. Imagens do Brasil na imprensa húngara e a emigração nas últimas décadas do século XIX. In: RINKE, Stefan (ed.). Entre espacios: la historia latinoamericana en el contexto global: Actas del XVII Congreso Internacional de la Asociación de Historiadores Latinoamericanistas Europeos (AHILA). Berlín: Freie Universität Berlín, 2016b. p. 408-414.

SZILÁGYI, Ágnes Judit. Magyarok Brazíliában és Portugáliában [Húngaros en Brasil y en Portugal]. Iberoamericana Quinqueecclesiensis, Pécs: PTE, v. 3, p. 145-166, 2005.

SZILÁGYI, Ágnes Judit. Metszéspontok: tanulmányok a portugál és a brazil történelemröl [Encrucijadas: Estudios sobre la historia portuguesa y brasileña]. Szeged: SZTE, 2009.

TATAI, Zoltán. Molnár Gábor élete, munkássága [Vida y obra de Gábor Molnár]. Ajka: “Bakonytól Amazóniáig” Molnár Gábor Társaság, 2009.

THURZÓ, Gábor. A brazíliai kérő [El pretendiente brasileño]. Budapest: Egy. Ny., 1942.

TORBÁGYI, Péter. Magyarok Latin-Amerikában [Húngaros en América Latina]. Budapest: A Magyar Nyelv és Kultúra Nemzetközi Társasága, 2004.

WILLANT, Rezső. A brazíliai "vörösszakáll" [Barba roja brasileño]. Budapest: [s. n.], 1940. 
La mirada perdida: los libros del escritor invidente Gábor Molnár sobre la Región Amazónica

\section{NOTAS}

${ }^{1}$ Sobre miembros de la emigración Kossuth en Brasil, véase Torbágyi, 2004, p. 34-38 y Szilágyi, 2016a, p. 115-124.

${ }^{2}$ Sobre la imagen de Brasil en la prensa húngara, véase también Szilágyi, 2016b, p. 408-414.

${ }^{3}$ En húngaro el apellido viene primero, y después el nombre o nombres. Por tanto aquí Jimenez erróneamente aparece como primer nombre (y sin acento). A pesar de que la persona en cuestión viene de Brasil, se mezclan aquí elementos de América del Sur (pampas - Argentina, llamas - los Andes). Las llamas son animales domésticos, y los puercoespines animales salvajes no domesticables. (¡No entraría en detalles sobre si es cierto que los puercoespines son más feos que los borregos!).

${ }^{4}$ (1920-1944). Sistema conservador y autoritario, encabezado por el contraalmirante y gobernador Miklós Horthy.

5 (Fiume, 1912-Budapest, 1989). Político. János Kádár lideró Hungría desde la intervención soviética que puso fin a la revolución de 1956, hasta 1988. El lema típico de su sistema, frecuentemente caracterizado como "comunismo de gulash", era: "los que no están contra nosotros, están con nosotros".

${ }^{6}$ Aunque ya había escrito en el periodo de entreguerras, lo que se podría considerar como negativo por el liderazgo cultural de izquierda, no tuvo que callar y sus obras fueron publicadas en la Hungría socialista. Una de las razones podría estar relacionada con sus raíces familiares muy humildes. Sus antepasados pertenecieron a la capa de obreros. Su padre era mesero, mientras los hombres de su línea materna por generaciones trabajaron como mineros cerca de Ajka en Csingervölgy. Creció en unas condiciones muy modestas con sus dos hermanos, criados por la madre, después de la muerte de su esposo de tuberculosis en 1920. Entonces Gábor Molnár tenía 12 años. En sus escritos no oculta su crítica acerca de las enormes diferencias sociales de la época Horthy.

${ }^{7}$ El apellido aparece como Molvar en el diario.

8 (Budapest, 1907-Nova Friburgo 1992). Nacido Pál Rónai. Traductor y profesor literario. Unas obras suyas publicadas en Hungría antes de la Segunda Guerra Mundial ya muestran un interés marcado hacia Brasil: compila y publica una antología de poesía contemporánea brasileña en 1939 y una selección de la poesía de Ribeiro Couto en 1940. Arribó a Rio de Janeiro en 1941. Una compilación de sus ensayos, seleccionados, fue publicada en húngaro por la Editorial Europa en 1981 bajo el título Latin és mosoly [Latino y sonrisa] (véase SPIRY, 2017, p. 105-111; SZILÁGYI, 2009, p. 108-109).

${ }^{9}$ (1915-2001). Ingeniero químico y diplomático. Luchó como voluntario en la guerra civil española. Fue condenado a 8 años en prisión en un pleito trotskista montado en 1949. Quedó rehabilitado en 1955. Fue el primer embajador de Hungría en Cuba, tras re-establecer nexos diplomáticos en 1960.

${ }^{10}$ Traductor literario y diplomático, más tarde embajador en varios países como México y Portugal. Fue asesor principal de Relaciones Exteriores del presidente Árpád Göncz. 
${ }^{11}$ Traducciones del libro Jaguárországban [En el país de los jaguares] vieron la luz en la Unión Soviética, Checoslovaquia y en Bulgaria, y una traducción de la obra $A$ dzsungel doktora [El doctor de la selva] fue publicada en Alemania del Este.

${ }^{12}$ Nacido József Hidasi. Después de leer e inspirarse en 1941 en el primer libro de Gábor Molnár, tuvo el sueño de llegar a Brasil, donde se asentó en 1950 (BANKOVICS, 2008, p. 77). Doctor en ciencias biológicas, coleccionista, fundador del Museo de Ornitología en Goiás en 1968, transformado recientemente en Museo de Zoología José Hidasi.

${ }^{13}$ Uno de los fundadores del parque nacional de Kiskunság, en la llanura húngara; jefe de la Colección de Aves del Museo de Ciencias Naturales de Hungría (1987-2007) y presidente del Asociación de Ornitología y de la Protección de la Naturaleza (Magyar Madártani és Természetvédelmi Egyesület) hasta 2011. Ha participado en varias expediciones científicas en Brasil.

${ }^{14}$ Las pérdidas incluyeron "la completa destrucción de la tercera colección de minerales más grande del mundo, [...] se quemaron 36 mil pájaros, 22 mil huevos, 13 mil peces, 40 mil anfibios y reptiles, 500 mil moluscos de las colecciones, y unos 100 mil libros y otras obras escritas cayeron presa de las llamas" (NAGY, 2014).

${ }^{15}$ Para la foto de uno de los reptiles, véase Molnár, 1964, anexo, foto no. 15. El título de la foto dice: "Una boa de 4 metros, regalo del autor. Foto tomada en el parque zoológico de Budapest".

${ }^{16}$ La asociación lleva el nombre de la autobiografía y último libro de Molnár A Bakonytól Amazóniáig [Desde Bakony hasta Amazonia] (MOLNÁR, 1978).

${ }^{17}$ La lista fue compilada con base en el catálogo de la Biblioteca Nacional de Hungría (Országos Széchényi Könyvtár) y Tatai, 2009, p. 214-218. Únicamente se indica la primera edición. (Aquí se enumeran solo los trabajos que se citaron en el artículo.)

Artículo recibido el 16 de enero de 2019.

Aprobado el 28 de mayo de 2019. 